\title{
Regional ventilation and gas exchange after hemicorporectomy
}

\author{
B. BAKE and G. GRIMBY \\ Departments of Clinical Physiology and Rehabilitation Medicine, University of Göteborg, \\ Göteborg, Sweden
}

\begin{abstract}
Bake, B. and Grimby, G. (1974). Thorax, 29, 366-370. Regional ventilation and gas exchange after hemicorporectomy. Maximum expiratory flow volume curves, gas exchange, closing volume, and regional distribution of lung volumes and ventilation were measured in a young man after hemicorporectomy.

The patient breathed at low lung volume, close to residual volume, and his total lung capacity was $63 \%$ of predicted normal. Maximum expiratory flows were normal at comparable lung volumes but the alveolo-arterial oxygen difference was increased at rest and during exercise. Closing volume exceeded functional residual capacity but was below predicted normal. Basal regions of the lungs were relatively hypoventilated and overexpanded.

Most of these findings are probably due to the low breathing mid-position and possibly also to other effects of altered abdominal mechanics.
\end{abstract}

Hemicorporectomy is an extremely radical operation, which has been undertaken in a very limited number of patients suffering from a malignant tumour of the pelvis or perineal area (Kennedy et al., 1960; Miller, Mackenzie, and Randall, 1966). Physical performance and cardiorespiratory function can be affected by the marked reduction of muscle mass and peripheral vascular bed.

We have previously reported basal metabolism, blood volume, physical working capacity, thermoregulation, and lung volumes after hemicorporectomy in a young man (Grimby and Stener, 1973). This patient had a reduced vital capacity and was breathing at an extremely low lung volume. Since a low breathing mid-position may change the distribution of ventilation (Dollfuss, Milic-Emili, and Bates, 1967; Milic-Emili et al., 1966) it was decided to study the regional distribution of ventilation, closing volume, and gas exchange in the same patient.

\section{Clinical DATA}

Hemicorporectomy was performed when the patient was 19 years of age because of a pelvic chondrosarcoma. The spinal column was divided between the fifth lumbar vertebra and the sacrum and the anterior abdominal wall above the pelvis.
A colostomy and an ileum bladder had been made three months previously. The patient tolerated the operation well and was successively mobilized. $\mathrm{He}$ was given a prosthesis, the upper part of which was formed as a cap enclosing the trunk. Below, the prosthesis replaced the removed pelvis and served as an anchorage for the hip joints. The upper part of the prosthesis reached to the nipple level and was fixed by loose braces but did not substantially limit expansion of the rib-cage $\dot{\delta}$ (Grimby and Stener, 1973). Six months later he had learnt to walk with the prosthesis using two o crutch-handled sticks and had started to take part in handicap sports. His body weight was $38 \mathrm{~kg}$ 음 compared to $58 \mathrm{~kg}$ before the operation when his height had been $185 \mathrm{~cm}$. He was a non-smoker $ᄋ$ and had no history of lung disease.

The present measurements were made six $\mathcal{W}^{N}$ months after the operation except for the closing volume and the repeat spirometry which were 0 done about three years postoperatively. The $\frac{}{\Phi}$ patient had no cardiorespiratory symptoms on $\stackrel{\oplus}{?}$ either occasion.

\section{METHODS}

All studies were performed with the patient sitting in his wheel-chair wearing the prosthesis. Spirometry 
was performed with a Bernstein spirometer and functional residual capacity was determined by the helium-dilution technique. All volumes are given in BTPS. Normal values were predicted according to Berglund et al. (1963) and Grimby and Söderholm (1963). Flow-volume curves were recorded during forced expiration using a 10-litre waterless spirometer (Electromed 780) and a Tektronix storage oscilloscope.

The regional lung volumes were studied by the xenon technique according to Milic-Emili et al. (1966) and Sutherland, Katsura, and Milic-Emili (1968) using 10 detectors in split collimators positioned dorsally. Regional washout curves after inhalation of xenon-133 were recorded during quiet breathing. The half-times $\left(\mathrm{T}_{\frac{1}{2}}\right)$ were measured, and the regional distribution index $\left[\mathrm{D}_{\mathrm{r}}(\mathrm{V} / \mathrm{V})\right]$, according to Bake, Fugl-Meyer, and Grimby (1972), was calculated using the formula:

$$
D_{\mathbf{r}}(\dot{V} / V)=\frac{n}{\sum \frac{1}{T_{\frac{1}{2}}}} \times \frac{100}{T_{\frac{1}{2}}}
$$

where $\mathrm{n}$ is the number of regions.

$\mathrm{D}_{\mathbf{r}}(\mathrm{V} / \mathrm{V})$ is proportional to regional ventilation to volume ratio.

Closing volume was measured with the $\mathrm{N}_{2}$ - technique according to Anthonisen, Danson, Robertson, and Ross (1969). The inspired volume of oxygen and expired gas volume were measured by a bag-in-box circuit and the nitrogen concentration at the mouth by a rapid nitrogen analyser (Nitralazer 505, Med. Science). Volume and $\mathrm{N}_{2 \text { - concentration were recorded }}$ on an X-Y recorder (Bryans 22020). The flow rate during the initial part of inspiration $(0.5$ 1.) and during expiration was below $0.3 \mathrm{l} / \mathrm{s}$.

The arterial pH, oxygen and carbon dioxide tensions were determined using Radiometer equipment. Expired air was collected in Douglas bags and analysed according to the micro-Scholander technique. Gas exchange measurements were performed at rest and during exercise on an arm-ergometer with successively increasing workloads of about six minutes' duration at each intensity.

\section{RESULTS AND DISCUSSION}

Figure 1 illustrates the extremely low functional residual capacity (FRC); only the inspiratory capacity is near to normal. At the vital capacity measurement, maximal diaphragmatic movement was 4-5 cm bilaterally; expiration from FRC to residual volume (RV) was associated with about $1 \mathrm{~cm}$ of diaphragmatic motion. This might be caused by a relatively small abdominal cavity with reduced abdominal compliance. The effect would be to push the diaphragm upwards and to impede downward movement. This could account for the reduced RV, FRC, and total lung capacity (TLC).

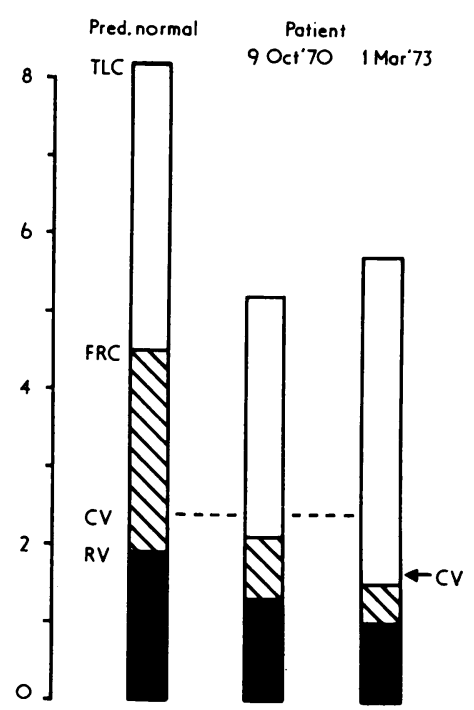

FIG. 1. On the left normal lung volumes predicted from patient's body height and weight before operation. On the right the measured lung volumes. The interrupted line indicates the predicted closing volume (CV).

The forced expiratory volume in one second $\left(F_{1}\right)$ was 3.51 ., which was $94 \%$ of the actual vital capacity (VC). It appears from the maximum expiratory flow volume curve, shown in Fig. 2, that the flow rate is close to predicted for comparable degrees of lung expansion. To the extent that the prediction is valid, this result would be compatible with close to normal upstream resistance and static recoil pressure of the lung (Mead, Turner, Macklem, and Little, 1967).

Figure 3 (left panel) illustrates the regional expansion for different overall lung volumes. The means of the right and left lungs are given.

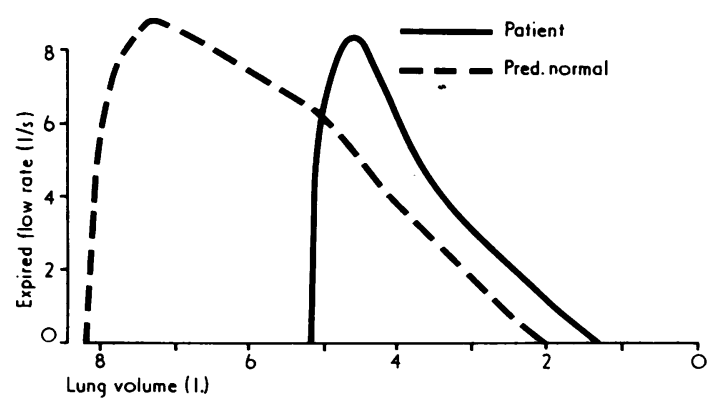

FIG. 2. Maximal expiratory flow-volume curves (predicted normal according to Wilhelmsen (1968)). 


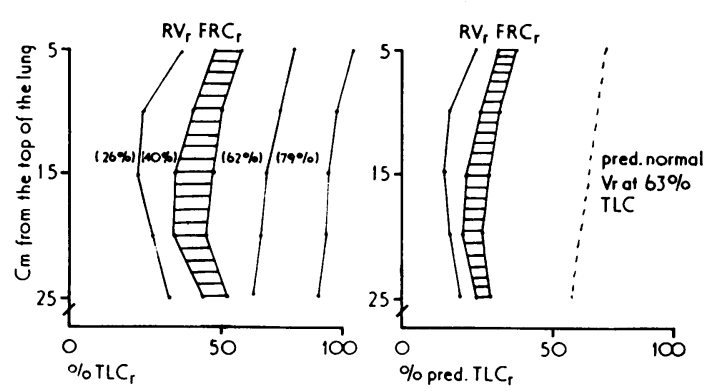

FIG. 3. (Left panel): Distribution of residual volume $\left(R V_{r}\right)$, functional residual capacity $\left(F R C_{r}\right)$, tidal volume during breathing (hatched area), and lung volumes corresponding to 63 and $79 \%$ of total lung capacity expressed as percentage of regional total lung capacity $\left(T L C_{r}\right)$. Numbers within parentheses indicate the overall lung volume in per cent TLC as measured spirometrically.

(Right panel): Distribution of corresponding lung volumes expressed as percentage of predicted regional

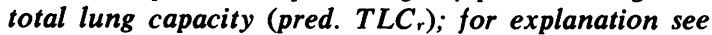
text. The dashed line represents the predicted normal distribution of regional lung volumes at $63 \%$ of TLC.

Normally the alveoli are successively more expanded up the lung (Milic-Emili et al., 1966; Glazier, Hughes, Maloney, and West, 1967), but this does not occur in this case. However, the present findings may not reflect true alveolar size because the TLC is reduced to about $63 \%$ of the predicted. If the lung parenchyma is assumed to be normal (there was no history of lung disease), it seems likely that when this patient has inhaled maximally, the degree of regional expansion corresponds to that in a normal subject who has inspired to about $63 \%$ of his TLC, when the apical alveoli are known to be larger than the basal (Milic-Emili et al., 1966). We attempt to correct for different alveolar size at TLC by expressing the present results in per cent of predicted normal regional lung volume at $63 \%$ of TLC (Bake et al., 1972).

Figure 3 (right panel) shows the regional expansion down the lung after this correction had been made and this probably reflects more closely alveolar size down the lung. The dashed line represents the predicted normal distribution of regional lung volumes at $63 \% \mathrm{TCL}$. In the patient, unlike the normal subject, the most basal region seems to be more expanded than the region above at RV and FRC. During a tidal volume inspiration the basal regions of the patient expand less than the middle region, whereas in a normal young subject tidal volume is distributed preferentially to the basal regions (Milic-Emili et al., 1966; Bake et al., 1972).

Figure $\mathbf{4}$ gives the regional 'dynamic' ventilation measured from the washout curves and, for comparison, average values for four young normal subjects. Because of low count rates the most apical region was unreliable and has been deleted. Clearly the upper parts of the patient's lungs are better ventilated than the basal parts, which is again the reverse of the normal situation. We therefore conclude that the basal regions of this patient's lung's are relatively underventilated and overexpanded.

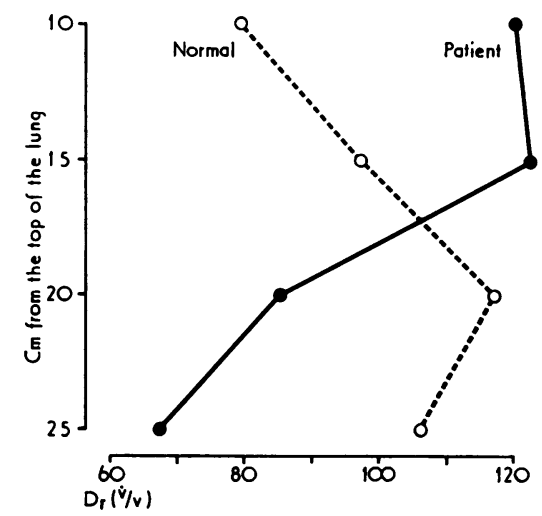

FIG. 4. Distribution of ventilation obtained from washout curves during quiet breathing. Average results from four young normal subjects are given. Regional distribution values $D_{r}(\dot{V} \mid V)$ are given as the regional percentage of the mean regional ventilation per unit volume (for explanation see text).

At low lung volume, airways in basal parts of the lungs may close (Dollfuss, Milic-Emili, and Bates, 1967). In this patient, airway closure was demonstrated at about $14 \%$ VC (Fig. 5), which somewhat exceeds FRC, as indicated on the right in Figure 1. Thus, airway closure occurs during normal tidal breathing, which provides a possible explanation for the low ventilation of the basal regions.

The gas exchange study (Table) demonstrates an increased alveolo-arterial oxygen difference at rest as well as during exercise but a normal physiological dead-space. This is compatible with the reduced basal ventilation leading to ventilation-perfusion inequality. The patient could reach an oxygen uptake of $1.31 \mathrm{1} / \mathrm{min}$ at a heart rate of 175 beats/min before stopping the exercise 


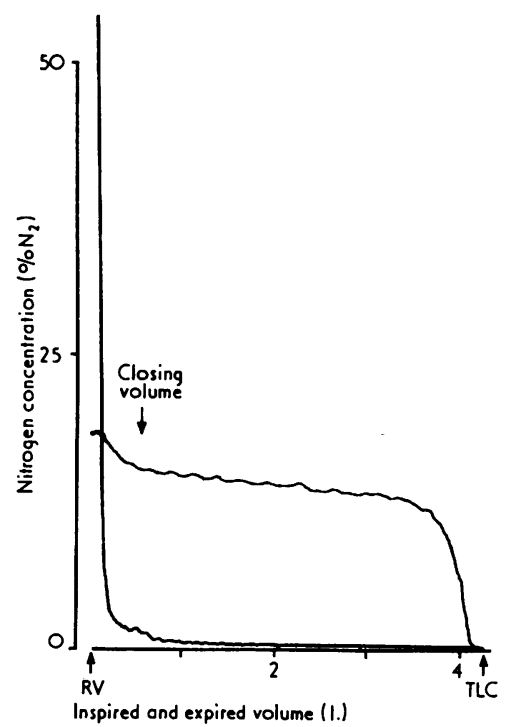

FIG. 5. A closing volume trace. The apparatus deadspace $(150 \mathrm{ml})$ containing expired air is first inhaled. Thereafter, nitrogen concentration approaches zero during oxygen inhalation. During expiration from $T L C$ the abrupt increase in nitrogen concentration at the end of expiration indicates the closing volume. The tracing is one of three almost identical recordings.

test due to fatigue. The arterial oxygen tension was kept normal, whereas the arterial carbon dioxide tension indicated slight hyperventilation at rest and during exercise.

Most of the present findings can be explained by the very low breathing mid-position. In this respect the results resemble the ventilation distri-

T A B L E RESULTS OF GAS EXCHANGE STUDY IN THE SITTING
POSITION AT REST AND DURING ARM-EXERCISE

\begin{tabular}{|c|c|c|c|c|}
\hline & \multirow{2}{*}{$\begin{array}{c}\text { At } \\
\text { Rest }\end{array}$} & \multicolumn{3}{|c|}{ Exercise } \\
\hline & & $25 W$ & $50 \mathrm{~W}$ & $75 \mathrm{~W}$ \\
\hline $\begin{array}{c}\text { Oxygen uptake } \\
(1 / \mathrm{min} \text { STPD }\end{array}$ & $0 \cdot 23$ & 0.61 & 0.86 & 1.32 \\
\hline $\begin{array}{l}\text { Ventilation } \\
\text { (1/min BTPS) }\end{array}$ & $6 \cdot 4$ & $17 \cdot 6$ & $26 \cdot 0$ & $50 \cdot 2$ \\
\hline $\begin{array}{l}\text { Respiratory rate } \\
\text { Heart rate } \\
\text { Arterial } \\
\text { oxygen tension } \\
\text { (mmHg) }\end{array}$ & $\begin{array}{l}16 \\
74 \\
76\end{array}$ & $\begin{array}{r}17 \\
105 \\
88\end{array}$ & $\begin{array}{r}15 \\
140 \\
88\end{array}$ & $\begin{array}{r}20 \\
175 \\
88\end{array}$ \\
\hline $\begin{array}{l}\text { Arterial carbon } \\
\text { dioxide tension } \\
(\mathrm{mmHg})\end{array}$ & 35 & 34 & 33 & 32 \\
\hline $\begin{array}{l}\text { Arterial pH } \\
\text { Alveolo-arterial } \\
\text { oxygen difference } \\
\text { (mmHg) }\end{array}$ & $28^{7 \cdot 42}$ & $24^{7 \cdot 40}$ & $29^{7 \cdot 39}$ & $33^{7 \cdot 32}$ \\
\hline$V_{D} / V_{T^{1}}$ & $0 \cdot 32$ & $0 \cdot 17$ & 0.06 & $0 \cdot 12$ \\
\hline
\end{tabular}

${ }^{1} V_{D} / V_{T}$ denotes the ratio between the physiological dead space and the tidal volume. bution in obese subjects (Holley, Milic-Emili, Becklake, and Bates, 1967). However, it is unclear how a low breathing mid-position could result in more expanded alveoli in the most basal region compared to the region just above (Fig. 3). It is also surprising, albeit fortunate, that the closing volume, although above the patient's FRC, is considerably below the predicted closing volume (McCarthy, Spencer, Greene, and Milic-Emili, 1972), as indicated in Figure 1. Possibly the operation and the prosthesis have induced other effects on the lungs besides low breathing mid-position and reduced lung volumes. In a previous study we were unable to demonstrate any effects of varying abdominal breathing patterns on ventilation distribution (Bake et al., 1972) and therefore it seems unlikely that an altered breathing pattern helps to explain the present findings. On the other hand, recent measurements in animals of pleural surface pressure have clearly demonstrated that evisceration results in much more even distending pressure from the lung (Agostoni, D'Angelo, and Bonanni, 1970; D'Angelo, Michelini, and Agostoni, 1971). Thus, the abdominal contents have a significant effect on regional lung expansion. To the extent that the hemicorporectomy resembles evisceration in animals this patient would have a reduced difference between apical and basal regional lung volumes. It may be that the particular combination of altered abdominal mechanics and low breathing mid-position in this patient can account for the results.

In conclusion, we have demonstrated reduced lung volumes, altered regional expansion, abnormal distribution of ventilation, airway closure during tidal breathing, and an increased alveoloarterial oxygen difference. In spite of these abnormalities the patient at present has no evidence of hypoxaemia and has a good physical working performance.

This study was supported by grants from the Swedish National Association against Heart and Chest Diseases and the Swedish Medical Research Council (project No. B73-14X-3888-01).

\section{REFERENCES}

Agostoni, E., D'Angelo, E., and Bonanni, M. V. (1970). The effect of the abdomen on the vertical gradient of pleural surface pressure. Respiration Physiology, 8, 332.

Anthonisen, N. R., Danson, J., Robertson, P. C., and Ross, W. R. D. (1969). Airway closure as a function of age. Respiration Physiology, 8, 58. 
Bake, B., Fugl-Meyer, A. R., and Grimby, G. (1972). Breathing patterns and regional ventilation distribution in tetraplegic patients and normal subjects. Clinical Science, 42, 117.

Berglund, E., Birath, G., Bjure, J., Grimby, G., Kjellmer, I., Sandqvist, L., and Söderholm, B. (1963). Spirometric studies in normal subjects I. Acta Medica Scandinavica, 173, 185.

D'Angelo, E., Michelini, S., and Agostoni, E. (1971). Partition of factors contributing to the vertical gradient of transpulmonary pressure. Respiration Physiology, 12, 90.

Dollfuss, R. E., Milic-Emili, J., and Bates, D. V. (1967). Regional ventilation of the lung studied with boluses of ${ }^{133}$ Xenon. Respiration Physiology, 2, 234.

Glazier, J. B., Hughes, J. M. B., Maloney, J. E., and West, J. B. (1967). Vertical gradient of alveolar size in lungs of dogs frozen intact. Journal of Applied Physiology, 23, 694.

Grimby, G. and Söderholm, B. (1963). Spirometric studies in normal subjects III. Acta Medica Scandinavica, 173, 199.

— and Stener, B. (1973). Physical performance and cardio-respiratory function after hemicorporectomy. Scandinavian Journal of Rehabilitation Medicine, 5, 124.

Holley, H. S., Milic-Emili, J., Becklake, M. R., and Bates, D. V. (1967). Regional distribution of pulmonary ventilation and perfusion in obesity. Journal of Clinical Investigation, 46, 475.
Kennedy, C. S., Miller, E. B., McLean, D. C., Perlis, M. S., Dion, R. M., and Horvitz, V. S. (1960). Lumbar amputation or hemicorporectomy for advanced malignancy of the lower half of the body. Surgery, 48, 357.

McCarthy, D. S., Spencer, R., Greene, R., and Milic-Emili, J. (1972). Measurement of 'closing volume' as a simple and sensitive test for early is detection of small airway disease. The American $\vec{\circ}$ Journal of Medicine, 52, 747.

Mead, J., Turner, J. M., Macklem, P. T., and Little, $\vec{\omega}$ J. B. (1967). Significance of the relationship be- $\stackrel{\sigma}{\circ}$ tween lung recoil and maximum expiratory flow. Journal of Applied Physiology, 22, 95.

Milic-Emili, J., Henderson, J. A. M., Dolovich, M. B., 으 Trop, D., and Kaneko, K. (1966). Regional $\omega$ distribution of inspired gas in the lung. Journal $\omega$ of Applied Physiology, 21, 749.

Miller, T. R., Mackenzie, A. R., and Randall, H. T. 은 (1966). Translumbar amputation for advanced cancer: Indications and physiologic alterations in four cases. Annals of Surgery, 164, 514.

Sutherland, P. W., Katsura, T., and Milic-Emili, J. (1968). Previous volume history of the lung and regional distribution of gas. Journal of A pplied Physiology, 25, 566.

Wilhelmsen, L. (1968). Lung mechanics in rheumatic valvular disease. Acta Medica Scandinavica, Supplement 489.

Requests for reprints to: Gunnar Grimby, M.D., Rehabilitation Medicine I, Sahlgrenska Sjukhuset S-413 45, Göteborg, Sweden. 